\title{
Choline-Deficient-Diet-Induced Fatty Liver Is a Metastasis-Resistant Microenvironment
}

\author{
MIKI NAKAMURA ${ }^{1}$, ATSUSHI SUETSUGU ${ }^{1,2,3}$, KOSUKE HASEGAWA ${ }^{1}$, \\ TAKURO MATSUMOTO ${ }^{1}$, HITOMI AOKI ${ }^{1}$, TAKAHIRO KUNISADA ${ }^{1}$, MASAHITO SHIMIZU $^{1}$, \\ SHIGETOYO SAJI ${ }^{1}$, HISATAKA MORIWAKI $^{1}$ and ROBERT M. HOFFMAN ${ }^{2,3}$ \\ ${ }^{1}$ Gifu University Graduate School of Medicine, Gifu, Japan; \\ ${ }^{2}$ AntiCancer, Inc., San Diego, CA, U.S.A.; \\ ${ }^{3}$ Department of Surgery, University of California, San Diego, CA, U.S.A.
}

\begin{abstract}
Background/Aim: Fatty liver disease is increasing in the developed and developing world. Liver metastasis from malignant lymphoma in the fatty liver is poorly understood. In a previous report, we developed color-coded imaging of the tumor microenvironment (TME) of the murine ELA-RFP malignant lymphoma during metastasis, including the lung. In the present report, we investigated the potential and microenvironment of the fatty liver induced by a cholinedeficient diet as a metastatic site in this mouse lymphoma model. Materials and Methods: C57BL/6-GFP transgenic mice were fed with a choline-deficient diet in order to establish a fatty liver model. ELA-RFP cells were injected in the spleen of normal mice and fatty-liver mice. Metastases in mice with fatty liver or normal liver were imaged with the Olympus SZX7 microscope and the Olympus FV1000 confocal microscope. Results: Metastases of EL4-RFP were observed in the liver, ascites and bone marrow. Primary tumors were imaged in the spleen at the injection site. The fewest metastases were observed in the fatty liver. In addition, the fewest cancer-associated fibroblasts (CAFs) were observed in the fatty liver. Conclusion: The relative metastatic resistance of the fatty liver may be due to the reduced number of CAFs in the fatty livers. The mechanism of the effect of the choline-deficient diet is discussed.
\end{abstract}

This article is freely accessible online.

Correspondence to: Atsushi Suetsugu, MD, Ph.D., Department of Gastroenterology, Gifu University Graduate School of Medicine, 1-1 Yanagido, Gifu 501-1194, Japan, Tel: +81 582306308, Fax: +81 582306310, e-mail: asue@gifu-u.ac.jp or Robert M. Hoffman, Ph.D., AntiCancer, Inc., 7917 Ostrow Street, San Diego, CA 92111, U.S.A. Tel: +1 8586542555, Fax: +1 8582684175, e-mail: all@anticancer.com

Key Words: EL4-RFP, malignant lymphoma, liver metastasis, choline-deficient diet, fatty liver, cancer-associated fibroblasts, methionine-dependence.
Non-alcoholic fatty liver disease (NAFLD) has increased in developed countries, with a prevalence of $20-30 \%$ in Europe and the United States and $12-30 \%$ in Asia (1-8). Obesity is a risk factor for NAFLD and has influenced the increase in NAFLD (9). An important question is whether fatty liver has an influence on cancer metastasis.

We have previously shown that murine EL4-RFP malignant lymphoma cells metastasize to multiple sites including the liver $(10,11)$. We have previously described color-coded imaging of the tumor microenvironment (TME) of cancer cells (11-20).

A syngeneic color-coded imageable lymphoma model, using the EL4 cell line, was previously developed to visualize recruitment of host stromal cells in the TME during metastasis. Large EL4-RFP liver metastases in C57BL/6GFP mice contained GFP-expressing stromal cells derived from the host (10). A subsequent study whereby liver metastases were formed after splenic injection of EL4-RFP cells also demonstrated that the liver metastases were rich in stromal cells including macrophages, fibroblasts, dendritic cells and normal lymphocytes (11).

In the present report, the TME of EL4-RFP metastasis in mice with fatty liver and normal liver were compared, with the use of EL4-RFP.

\section{Materials and Methods}

GFP transgenic mice. Transgenic C57BL/6-GFP mice were obtained from the Research Institute for Microbial Diseases (Osaka University, Osaka, Japan). The C57BL/6-GFP mice expressed Aequorea victoria GFP under the control of the chicken $\beta$-actin promoter and cytomegalovirus enhancer (21). Eight-week-old GFP immunocompetent C57BL/6-GFP transgenic mice were used as the host for RFP-EL4 lymphoma cells. Fatty liver was generated in C57BL/6-GFP mice $(n=3)$ on a choline-deficient diet (CDD) for 4 weeks (22). Another group of mice $(n=3)$ were provided with the control diet (CD) for 4 weeks until the end of the experiment. Diets were purchased from Oriental Yeast Co. Ltd., Tokyo. 
Cell line and culture conditions. EL-4, a mouse lymphoma cell line, was previously established from a lymphoma induced in a C57BL/6 mouse by 9,10 -dimethyl-1, 2-benzanthracene $(10,11)$. The cells were maintained in RPMI 1640 supplemented with $10 \%$ heatinactivated fetal bovine serum (FBS), $1 \%$ penicillin and streptomycin (Gibco-BRL, Grand Island, NY). The cells were cultured in a humidified atmosphere containing $5 \% \mathrm{CO}_{2}$ at $37^{\circ} \mathrm{C}$.

Red fluorescent protein (RFP) transduction of lymphoma cells. EL4 lymphoma cells were labeled with RFP as previously reported using retrovirus-based vector expressing $\operatorname{RFP}(10,11,14,23-25)$.

Color-coded lymphoma-host liver model. EL4-RFP mouse malignant lymphoma cancer cells $\left(2.0 \times 10^{6}\right)$ were injected in the spleen of mice on day 14, after the start of the CDD or CD. All mice were sacrificed on day 28. EL4-RFP lymphoma cells, growing in vitro, were harvested and washed three times with cold serumfree medium and then re-suspended with serum-free RPMI 1640 medium. EL4-RFP lymphoma cells were then injected in the spleen of C57BL/6-GFP transgenic mice. Liver metastases tumors, primary tumors in the spleen, ascites and bone marrow cells were cultured for several weeks from CD and CDD mice $(10,11)$.

Ex vivo imaging. The SZX7 microscope and FV1000 confocal microscope (Olympus Corp. Tokyo, Japan) were used for imaging.

Histology. Tumors were prepared for histological analysis using including hematoxylin and eosin (H\&E) staining using previously published protocols (26).

Statistical analysis. All data are expressed as the mean \pm SD and analyzed using the two-sided $t$-test. Differences were considered significant when the two-sided $p$-value was less than 0.05 .

Study approval. All experiments were conducted in accordance with the Institutional Guidelines of Gifu University and were approved by the Animal Research Committee and the Committee on Living Modified Organisms of Gifu University.

\section{Results and Discussion}

Establishment of a fatty liver model. To establish a fatty liver mouse model, C57BL/6-GFP mice were fed a cholinedeficient diet (CDD) for 4 weeks. Mice were divided into two groups, a CDD group and a control-diet (CD) group. In each group, EL-4-RFP metastases were observed in the liver, ascites and bone marrow, as well as in the spleen at the primary injection site.

Metastases in normal and fatty liver. Multiple liver metastases and primary tumors in the spleen were observed in each group (Figure 1A). CD mice had more liver metastases than CDD mice (Figure 1B,C). Many lipid droplets were formed in the CDD mice liver (Figure 1C), indicating that liver became fatty on the CDD. H\&E staining showed that many lipid droplets occupied the liver tissue (Figure 1D) and fewer cancer cells were observed in the
CDD mice, while larger masses of cancer cells were formed in the livers of CD mice (Figure 1A, B). Fewer EL-4 RFP cells and GFP stromal cells, such as fibroblasts were observed in the liver of CDD mice than in CD mice (Figure 1C). On the other hand, in the spleen, there were no significant differences in the tumors size between CD mice and CDD mice (Figure 1C).

Comparison of cells from metastases in fatty and normal liver and other organs cultured in vitro. Liver metastases, primary tumors in the spleen, ascites and bone marrow cells were cultured for several weeks from CD and CDD mice. Phagocytic cells were observed in liver metastases from both CDD and CD mice on day 7 (Figure 2A). Dendritic cells and cancer-associated fibroblasts (CAFs) were also observed in liver metastasis in $\mathrm{CD}$ mice, and dendritic cells were observed in CDD mice on day 14 (Figure 2B). CAFs were observed in the spleen of CD and CDD mice (Figure 2C). EL4-RFP lymphoma cells were abundant in ascites (Figure 2D).EL4-RFP cells were observed in the bone-marrow culture (Figure 2E). Bone-marrow cultures contained EL4-RFP cells. Fewer CAFs were observed in the liver metastasis from CDD mice than $\mathrm{CD}$ mice (Figure $2 \mathrm{~F}$ ).

It should be noted that CDD-fed rodents have lower methionine levels, as choline is a precursor of methionine (27-38), which may inhibit tumor growth in the liver, due to the enhanced requirement of cancer cells for methionine.

\section{Conclusion}

Liver metastasis from colorectal cancer is less frequently observed in patients with hepatic steatosis than in patients with normal liver $(21,30)$ which may be related to the present study, where an analogous result was obtained with reduction of EL4-RFP metastases in the fatty liver along with fewer CAFs. The fatty liver may not be a suitable

Figure 1. (A) Bright-field and fluorescence imaging of the liver and spleen. RFP-expressing tumors were observed in the liver and spleen of $C D$ and $C D D$ mice. White arrows indicate liver metastases. Blue arrows indicate primary tumors in the spleen. All images were captured with the Olympus SZX7 microscope. Bar $=10 \mathrm{~mm}$. (B) Left bar graphs depict the number of metastases in the liver. Right bar graphs depict the size of the primary tumor. (C) High-magnification images of liver metastasis and primary tumors in the spleen. White arrows indicate EL4-RFP lymphoma cells. Yellow arrows indicate lipid droplets. Red arrows indicate blood cells. All images were captured with the Olympus FV1000 confocal microscope. Bar $=100 \mu m$. (D) Histopathological analysis with $H \& E$-stained sections. Red arrows indicate the tumor in the $C D$ mouse liver. Yellow arrows indicate lipid droplets in the CDD mouse liver. Blue arrows indicate lymphoma cells. Bar=100 $\mu \mathrm{m}$. 

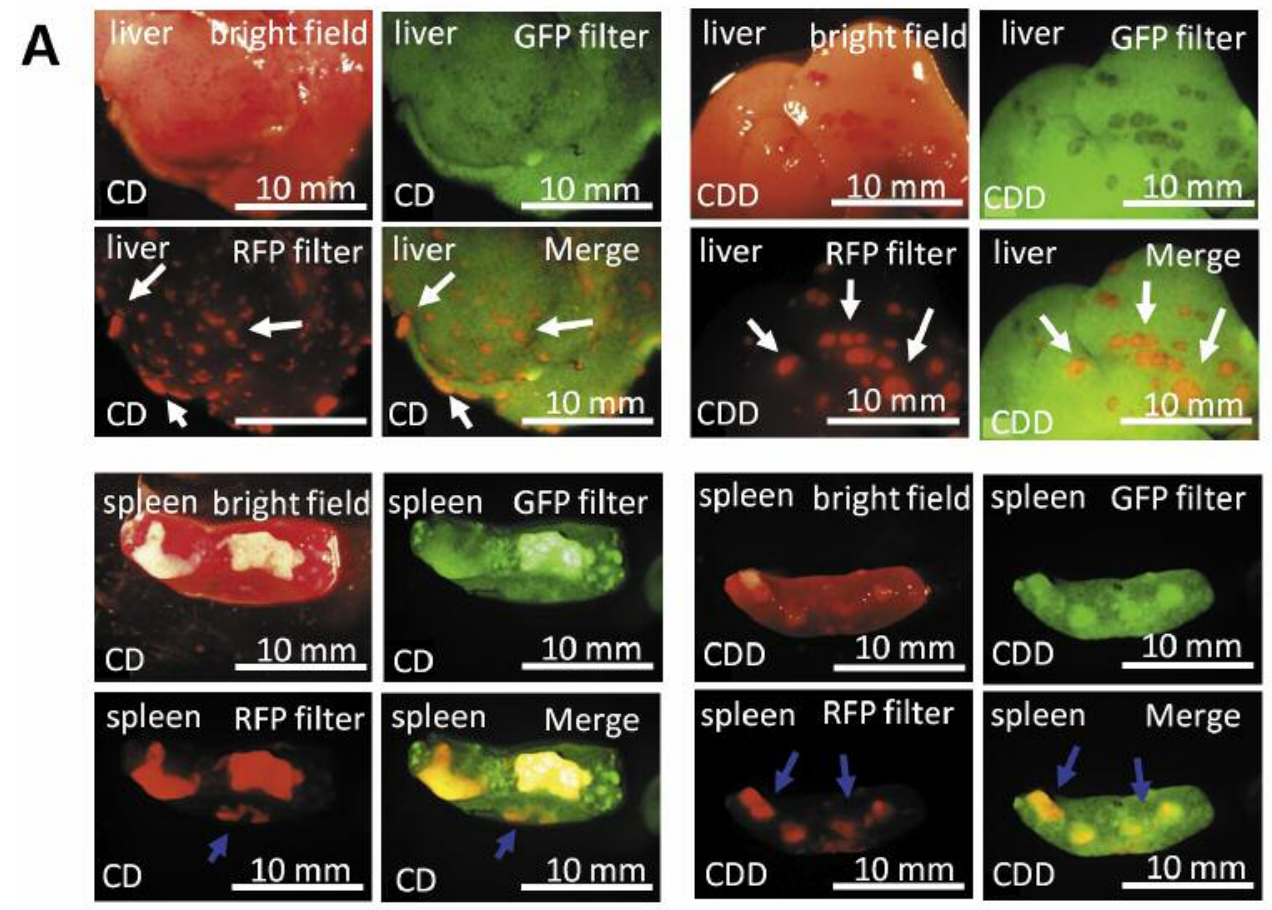
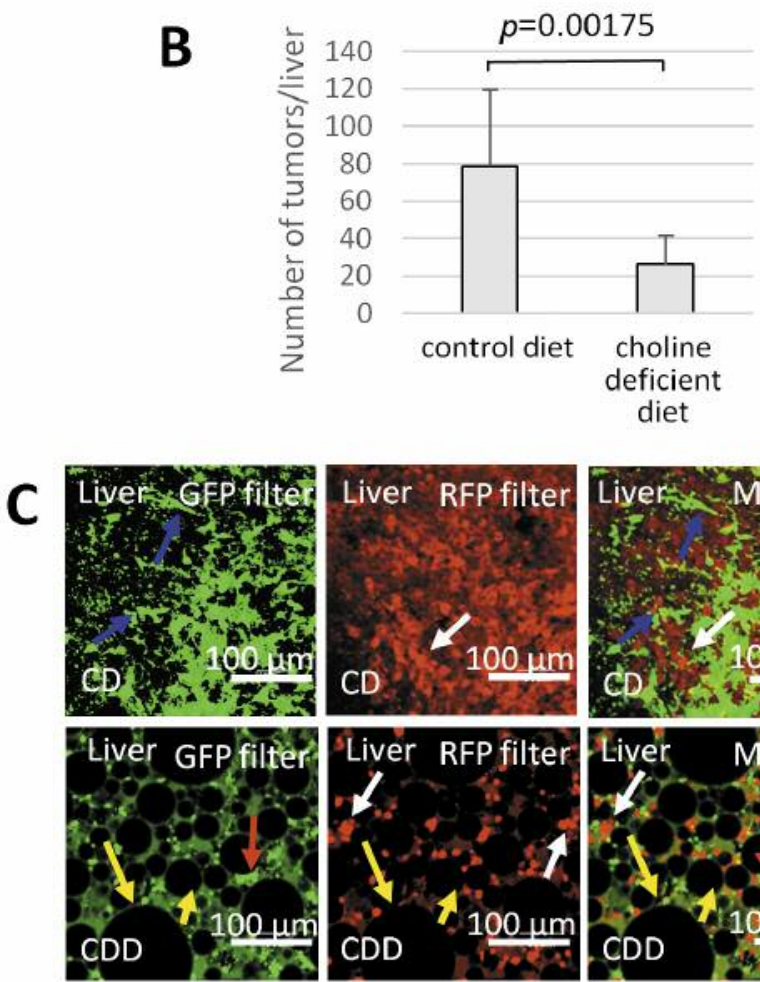
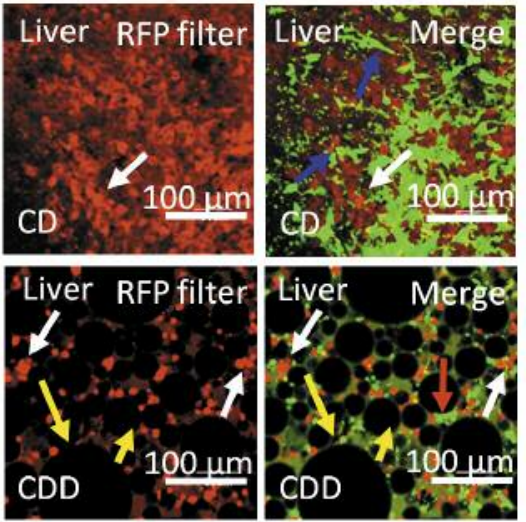

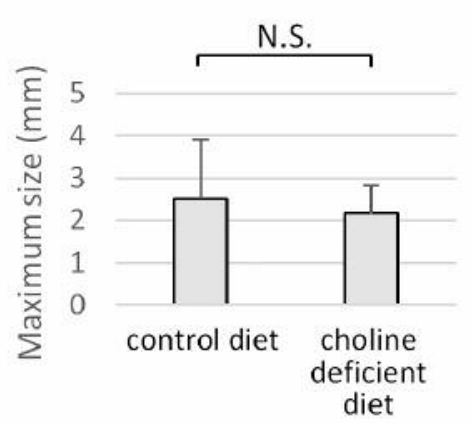

D
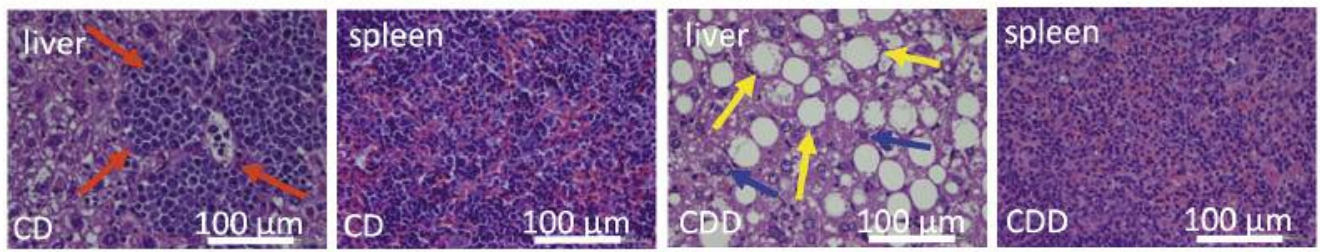

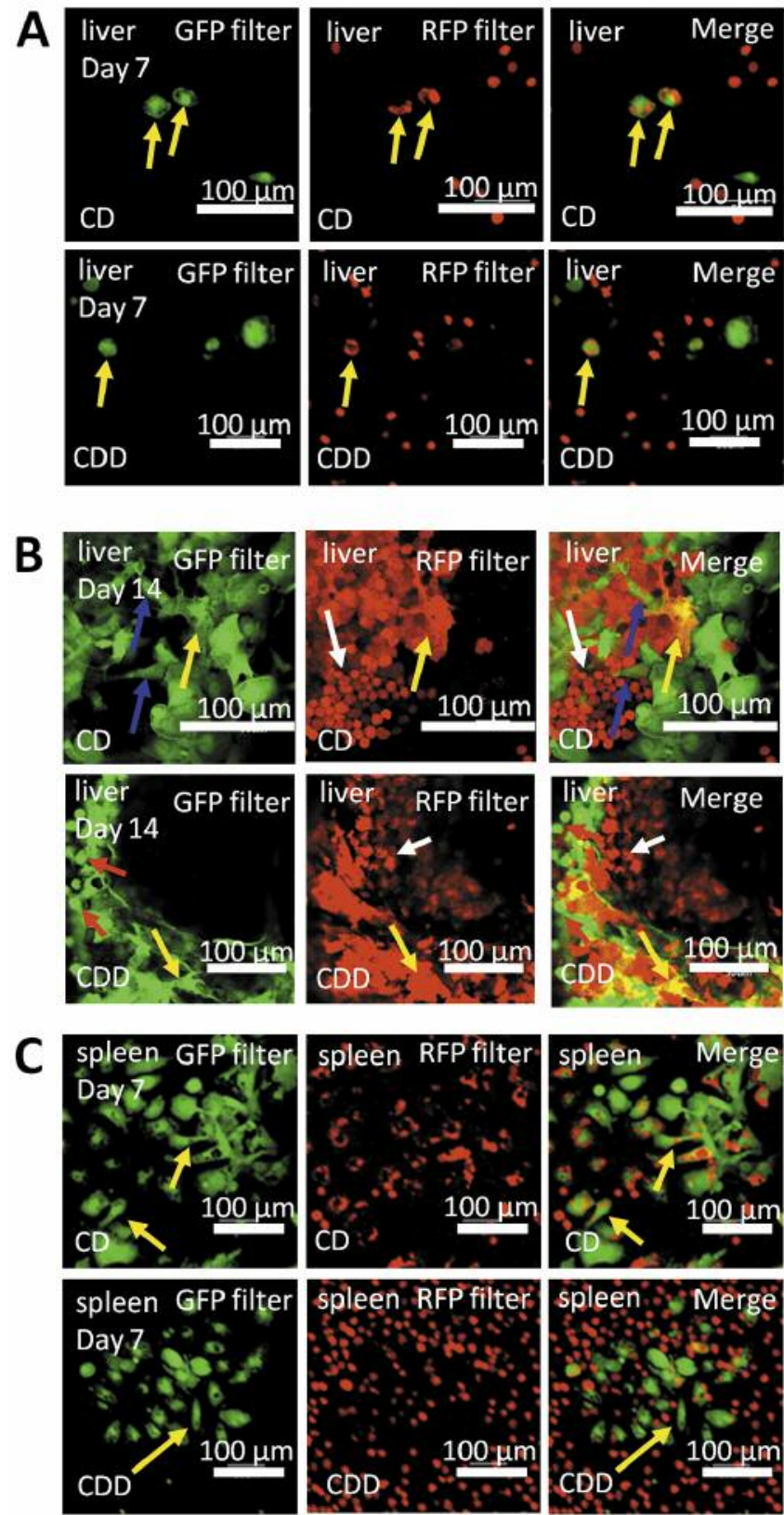
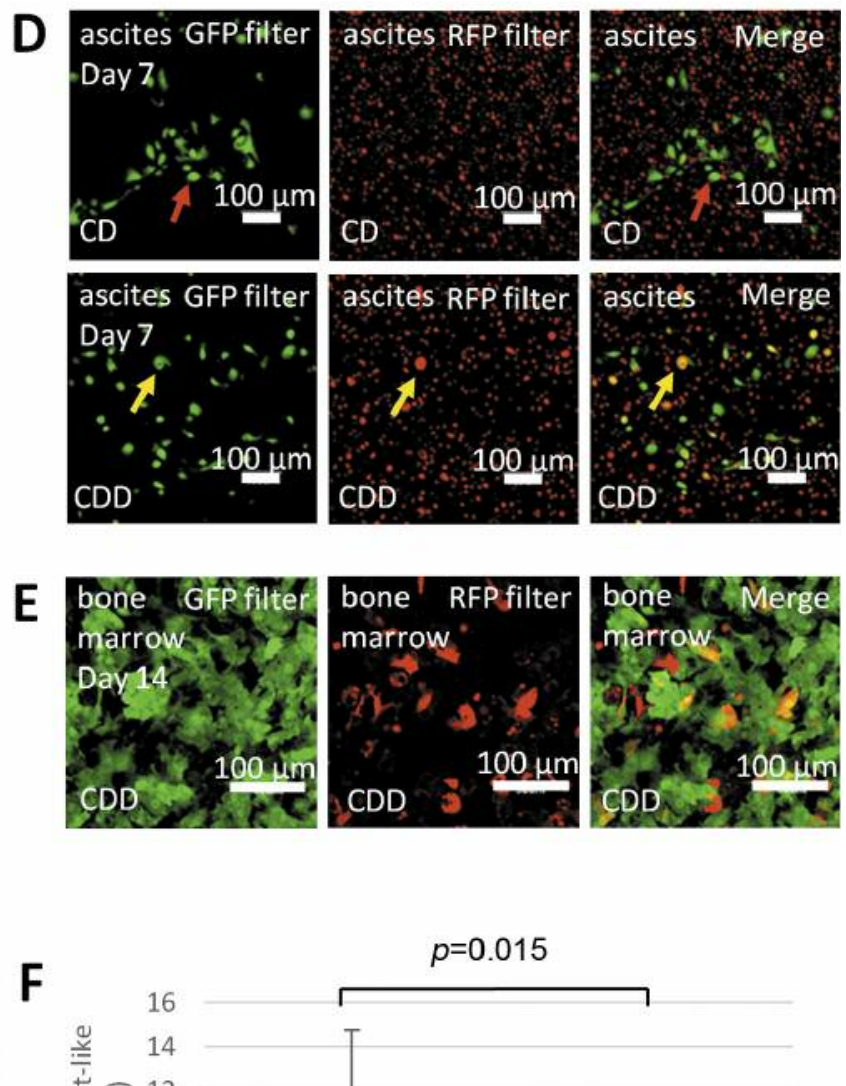

Figure 2. High-magnification images of cells cultured from tumors and metastases, which were harvested from the CD and CDD mice. Images were obtained with the Olympus FV1000 confocal microscope. $C D=$ control diet $C D D=$ choline deficient diet. Bar=100 $\mu$ m. (A) Cultures of liver metastases in $C D$ and $C D D$ mice on day 7. Yellow arrows indicate phagocytosis. (B) Cultures of liver metastases from CD and CDD mice on day 14 . White arrows indicate EL4-RFP cells. Blue arrows indicate cancer-associated fibroblasts (CAFs). Yellow arrows indicate dendritic cells. (C) Cultures of EL4-RFP lymphoma from the spleen of CD and CDD mice on day 7. Yellow arrows indicate CAFs. (D) Cultures of EL-4-RFP lymphoma ascites from $C D$ and $C D D$ mice on day 7. Red arrows indicate blood cells. Yellow arrows indicate phagocytosis. (E) Cultures of bone marrow from CD and CDD mice on day 7 after EL-4-RFP implantation. Abundant EL4-RFP lymphoma cells and stromal cells expressing GFP were observed. (F) The number of CAFs in the liver was counted. Values are expressed as mean $\pm S D$.

environment for CAFs which may be due to re-programmed methionine metabolism which may have occurred during the time the animals were on the CDD (31-46); and as a result, fewer liver metastases were formed.

\section{Conflicts of Interest}

None of the authors have any conflict of interest in regard to this study. 


\section{References}

1 Williams CD, Stengel J, Asike MI, Torres DM, Shaw J, Contreras M, Landt CL and Harrison SA: Prevalence of nonalcoholic fatty liver disease and nonalcoholic steatohepatitis among a largely middle-aged population utilizing ultrasound and liver biopsy: a prospective study. Gastroenterology 140: 124131, 2011.

2 Vernon G, Baranova A, and Younossi ZM: Systematic review: the epidemiology and natural history of non-alcoholic fatty liver disease and non-alcoholic steatohepatitis in adults. Aliment Pharmacol Ther 34: 274-285, 2011.

3 Radu C, Grigorescu M, Crisan D, Lupsor M, Constantin D, and Dina L: Prevalence and associated risk factors of non-alcoholic fatty liver disease in hospitalized patients. J Gastrointestin Liver Dis 17: 255-260, 2008.

4 Angulo P. GI epidemiology: nonalcoholic fatty liver disease. Alimentary Pharmacol Ther 25: 883-889, 2007.

5 Bae JC, Cho YK, Lee WY, Seo HI, Rhee EJ, Park SE, Park CY, Oh KW, Sung KC and Kim BI: Impact of nonalcoholic fatty liver disease on insulin resistance in relation to HbAlc levels in nondiabetic subjects. Am J Gastroenterology 105: 2389-2395, 2010.

6 Das K, Das K, Mukherjee PS, Ghosh A, Ghosh S, Mridha AR, Dhibar T, Bhattacharya B, Bhattacharya D, Manna B, Dhali GK, Santra A and Chowdhury A: Nonobese population in a developing country has a high prevalence of nonalcoholic fatty liver and significant liver disease. Hepatology 51: 1593-1602, 2010.

7 Hou XH, Zhu YX, Lu HJ, Chen HF, Li Q, Jiang S, Xiang KS and Jia WP. Non-alcoholic fatty liver disease's prevalence and impact on alanine aminotransferase associated with metabolic syndrome in the Chinese. J Gastroenterology Hepatology 26: 722-730, 2011.

8 Chen ZW, Chen LY, Dai HL, Chen JH and Fang LZ: Relationship between alanine aminotransferase levels and metabolic syndrome in nonalcoholic fatty liver disease. J Zhejiang University Science B 9: 616-622, 2008.

9 Starley BQ, Calcagno CJ and Harrison SA: Nonalcoholic fatty liver disease and hepatocellular carcinoma: a weighty connection. Hepatology 51: 1820-1832, 2010.

10 Matsumoto T, Suetsugu A, Shibata Y, Nakamura N, Aoki H, Kunisada T, Tsurumi H, Shimizu M and Hoffman RM: A colorcoded imageable syngeneic mouse model of stromal-cell recruitment by metastatic lymphoma. Anticancer Res 35: 46474654, 2015.

11 Matsumoto T, Suetsugu A, Hasegawa K, Nakamura M, Aoki H, Kunisada T, Tsurumi H, Shimizu M and Hoffman RM: Colorcoded imaging of syngeneic orthotopic malignant lymphoma interacting with host stromal cells during metastasis. Anticancer Res 36: 1473-1478, 2016.

12 Yang M, Li L, Jiang P, Moossa AR, Penman S and Hoffman RM: Dual-color fluorescence imaging distinguishes tumor cells from induced host angiogenic vessels and stromal cells. Proc Natl Acad Sci USA 100: 14259-14262, 2003.

13 Amoh Y, Yang M, Li L, Reynoso J, Bouvet M, Moossa AR, Katsuoka K and Hoffman RM: Nestin-linked green fluorescent protein transgenic nude mouse for imaging human tumor angiogenesis. Cancer Res 65: 5352-5357, 2005.

14 Hoffman RM and Yang M: Color-coded fluorescence imaging of tumor-host interactions. Nature Protoc 1: 928-935, 2006.
15 Bouvet M, Tsuji K, Yang M, Jiang P, Moossa AR and Hoffman $\mathrm{RM}$ : In vivo color-coded imaging of the interaction of colon cancer cells and splenocytes in the formation of liver metastases. Cancer Res 66: 11293-11297, 2006.

16 Suetsugu A, Osawa Y, Nagaki M, Saji S, Moriwaki H, Bouvet $M$ and Hoffman RM: Imaging the recruitment of cancerassociated fibroblasts by liver-metastatic colon cancer. J Cell Biochem 112: 949-953, 2011.

17 Suetsugu A, Katz M, Fleming J, Truty M, Thomas R, Saji S, Moriwaki $\mathrm{H}$, Bouvet $\mathrm{M}$ and Hoffman RM: Imageable fluorescent metastasis resulting in transgenic GFP mice orthotopically implanted with human-patient primary pancreatic cancer specimens. Anticancer Res 32: 1175-1180, 2012.

18 Suetsugu A, Katz M, Fleming J, Truty M, Thomas R, Moriwaki H, Bouvet M, Saji S and Hoffman RM: Multi-color palette of fluorescent proteins for imaging the tumor microenvironment of orthotopic tumorgraft mouse models of clinical pancreatic cancer specimens. J Cell Biochem 113: 2290-2295, 2012.

19 Suetsugu A, Katz M, Fleming J, Truty M, Thomas R, Saji S, Moriwaki H, Bouvet $M$ and Hoffman RM: Non-invasive fluorescent-protein imaging of orthotopic pancreatic-cancerpatient tumorgraft progression in nude mice. Anticancer Res 32: 3063-3067, 2012.

20 Hoffman RM: Transgenic nude mice ubiquitously expressing fluorescent proteins for color-coded imaging of the tumor microenvironment. Methods Mol Biol 1194: 353-365, 2014.

21 Okabe M, Ikawa M, Kominami K, Nakanishi T and Nishimune Y: "Green mice" as a source of ubiquitous green cells. FEBS Lett 407: 313-319, 1997.

22 Copeland DH and Salmon WD: The occurrence of neoplasms in the liver, lungs, and other tissues of rats as a result of prolonged choline deficiency. Am J Pathol 22: 1059-1079, 1946.

23 Hoffman RM and Yang M: Subcellular imaging in the live mouse. Nature Protoc 1: 775-782, 2006.

24 Hoffman RM: The multiple uses of fluorescent proteins to visualize cancer in vivo. Nature Rev Cancer 5: 796-806, 2005.

25 Hoffman RM and Yang M: Whole-body imaging with fluorescent proteins. Nature Protoc 1: 1429-1438, 2006.

26 Igarashi K, Kawaguchi K, Kiyuna T, Murakami T, Miwa S, Nelson SD, Dry SM, Li Y, Singh A, Kimura H, Hayashi K, Yamamoto N, Tsuchiya H, Eilber FC and Hoffman RM: Patient-derived orthotopic xenograft (PDOX) mouse model of adult rhabdomyosarcoma invades and recurs after resection in contrast to the subcutaneous ectopic model. Cell Cycle 16: 9194, 2017.

27 Murono K, Kitayama J, Tsuno NH, Nozawa H, Kawai K, Sunami E, Akahane $M$ and Watanabe T: Hepatic steatosis is associated with lower incidence of liver metastasis from colorectal cancer. Intl J Colorectal Dis 28: 1065-1072, 2013.

28 Tamura R, Masuda H, Ishii Y and Nemoto N: Relationship between fatty liver and liver metastasis in rats given injection of rat colon cancer cell line. Hepato-gastroenterology 46: 167-171, 1999.

29 Hayashi S, Masuda H and Shigematsu M: Liver metastasis rare in colorectal cancer patients with fatty liver. Hepatogastroenterology 44: 1069-1075, 1997.

30 Karube H, Masuda H, Hayashi S, Ishii Y and Nemoto N: Fatty liver suppressed the angiogenesis in liver metastatic lesions. Hepato-gastroenterology 47: 1541-1545, 2000. 
31 Hoffman RM and Erbe RW: High in vivo rates of methionine biosynthesis in transformed human and malignant rat cells auxotrophic for methionine. Proc Natl Acad Sci USA 73: 15231527, 1976.

32 Hoffman RM, Jacobsen SJ and Erbe RW: Reversion to methionine independence in simian virus 40-transformed human and malignant rat fibroblasts is associated with altered ploidy and altered properties of transformation. Proc Natl Acad Sci USA 76: 1313-1317, 1979.

33 Jacobsen SJ, Hoffman RM and Erbe RW: Regulation of methionine adenosyltransferase in normal diploid and SV40-transformed human fibroblasts. J Natl Cancer Inst 65: 1237-1244, 1980.

34 Coalson DW, Mecham JO, Stern PH and Hoffman RM: Reduced availability of endogenously synthesized methionine for Sadenosylmethionine formation in methionine dependent cancer cells. Proc Natl Acad Sci USA 79: 4248-4251, 1982.

35 Diala ES and Hoffman RM: Hypomethylation of HeLa cell DNA and the absence of 5-methylcytosine in SV40 and adenovirus (type 2) DNA: analysis by HPLC. Biochem Biophys Res Commun 107: 19-26, 1982.

36 Mecham JO, Rowitch D, Wallace CD, Stern PH and Hoffman RM: The metabolic defect of methionine dependence occurs frequently in human tumor cell lines. Biochem Biophys Res Commun 117: 429-434, 1983

37 Stern PH, Mecham JO, Wallace CD and Hoffman RM: Reduced free-methionine in methionine-dependent SV40-transformed human fibroblasts synthesizing apparently normal amounts of methionine. J Cell Physiol 117: 9-14, 1983.

38 Hoffman RM: Altered methionine metabolism, DNA methylation and oncogene expression in carcinogenesis: a review and synthesis. Biochim Biophys Acta Rev Cancer 738: 49-87, 1984.
39 Stern PH and Hoffman RM: Elevated overall rates of transmethylation in cell lines from diverse human tumors. In Vitro - Rapid Commun in Cell Biology 20: 663-670, 1984.

40 Stern PH, Wallace CD and Hoffman RM: Altered methionine metabolism occurs in all members of a set of diverse human tumor cell lines. J Cell Physiol 119: 29-34, 1984.

41 Stern PH and Hoffman RM: Enhanced in vitro selective toxicity of chemotherapeutic agents for human cancer cells based on a metabolic defect. J Natl Cancer Inst 76: 629-639, 1986.

42 Guo H, Lishko V, Herrera H, Groce A, Kubota T and Hoffman RM: Therapeutic tumor-specific cell-cycle block induced by methionine starvation in vivo. Cancer Res 53: 5676-5679, 1993.

43 Hoffman RM: The wayward methyl group and the cascade to cancer. Cell Cycle 16: 825-829, 2017.

44 Hoffman RM: Development of recombinant methioninase to target the general cancer-specific metabolic defect of methionine dependence: a 40-year odyssey. Expert Opin Biol Ther 15: 21$31,2015$.

45 Hoffman RM: Is DNA methylation the new guardian of the genome? Mol Cytogenet 10: 11, 2017.

46 Hoffman RM and Jacobsen SJ: Reversible growth arrest in simian virus 40 -transformed human fibroblasts. Proc Natl Acad Sci USA 77: 7306-7310, 1980 